\title{
Molecular diagnosis and genotype analysis of Giardia duodenalis in asymptomatic children from a rural area in central Colombia
}

\author{
Juan David Ramírez ${ }^{\mathrm{a}, *}$, Rubén Darío Heredia ${ }^{\mathrm{b}}$, Carolina Hernández ${ }^{\mathrm{a}}$, Cielo M. León ${ }^{\mathrm{a}}$, Ligia Inés Moncada ${ }^{\mathrm{b}}$, \\ Patricia Reyes $^{\mathrm{b}}$, Análida Elizabeth Pinilla ${ }^{\mathrm{c}}$, Myriam Consuelo Lopez $^{\mathrm{b}}$ \\ ${ }^{a}$ Grupo de Investigaciones Microbiológicas - UR (GIMUR), Facultad de Ciencias Naturales y Matemáticas, Universidad del Rosario, Bogotá, Colombia \\ ${ }^{\mathrm{b}}$ Departamento de Salud Pública, Facultad de Medicina, Universidad Nacional de Colombia, Bogotá, Colombia \\ ${ }^{\mathrm{c}}$ Departamento de Medicina, Facultad de Medicina, Universidad Nacional de Colombia, Bogotá, Colombia
}

\section{A R T I C L E I N F O}

\section{Article history:}

Received 10 November 2014

Received in revised form 9 March 2015

Accepted 12 March 2015

Available online 18 March 2015

\section{Keywords:}

Molecular epidemiology

Assemblages

Genotypes

PCR

Diagnosis

Giardiasis

\begin{abstract}
A B S T R A C T
Giardiasis is a parasitic infection that affects around 200 million people worldwide. This parasite presents a remarkable genetic variability observed in 8 genetic clusters named as 'assemblages' (A-H). These assemblages are host restricted and could be zoonotic where A and B infect humans and animals around the globe. The knowledge of the molecular epidemiology of human giardiasis in South-America is scarce and also the usefulness of PCR to detect this pathogen in fecal samples remains controversial. The aim of this study was to conduct a cross-sectional study to compare the molecular targets employed for the molecular diagnosis of Giardia DNA and to discriminate the parasite assemblages circulating in the studied population. We analyzed 181 fecal samples from Children at La Virgen, Cundinamarca, Colombia that were DNA-extracted and analyzed by SSU rDNA, tpi and gdh loci. We observed positivity by microscopy of $13 \%$ and by PCR around $76-80 \%$ depending on the molecular marker. Additionally, a lack of statistical concordance between microscopy and PCR was detected. Regarding the genetic assemblages, we detected assemblage A (3\%), assemblage B (90\%) and mixed infections assemblages A + B (7\%). Hence, the subassemblages were typed as AI, AII, BIII and BIV across the population. This study represents a reliable attempt to understand the molecular epidemiology of giardiasis in Colombia and the use of PCR to detect cryptic infections. The epidemiological implications are herein discussed.
\end{abstract}

(c) 2015 Elsevier B.V. All rights reserved.

\section{Introduction}

The protozoan parasite Giardia duodenalis (syn. Giardia intestinalis, Giardia lamblia) infects a wide range of vertebrates including humans, domestic and wild animals. This cosmopolitan parasite is re-emerging as one of the most frequent causes of diarrhea in humans from developing countries and is considered as one of the most common parasitic infection with 200 million people infected worldwide representing a serious public health concern (Ryan and Cacciò, 2013). In some cases the infection is asymptomatic and when symptoms occur they may range from chronic diarrhea, abdominal pain to severe malabsorption, having an adverse impact on growth and intellectual development (Feng and Xiao, 2011; Haque et al., 2005). Children, in special those living in developing countries and living in rural communities, are most at risk from the clinical consequences of Giardia infection. In September 2004, giardiasis was included in the 'Neglected

\footnotetext{
* Corresponding author.

E-mail address: juand.ramirez@urosario.edu.co (J.D. Ramírez).
}

Diseases Initiative' of the WHO (Savioli et al., 2006) demonstrating the epidemiological relevance of this infection. In Colombia, Giardia prevalence ranges from $11 \%$ to $61 \%$ in studies conducted in children, representing a concern in terms of public health (Giraldo-Gómez et al., 2005; Chaves Mdel et al., 2007; LoraSuárez et al., 2002; Rodríguez et al., 2014).

Isolates of $G$. duodenalis are currently grouped into 8 recognized genotypic clusters or 'assemblages' $(\mathrm{A}-\mathrm{H})$, based on molecular genetic analyses at limited and highly conserved loci. Assemblages A and B are zoonotic, whereas C, D, E, F, G, and $\mathrm{H}$ are defined as host restricted (Thompson, 2000; Monis and Thompson, 2003; Monis et al., 2009; Andrews et al., 1998). Human infective assemblages (A and $B$ ) have been further subgrouped using conserved loci such as glutamate dehydrogenase ( $g d h)$ and triose phosphate isomerase (tpi) accordingly: AI, AII, BIII, and BIV with no strict associations based on clinical presentation (Monis et al., 1998; Ryan and Cacciò, 2013; Thompson, 2002). G. duodenalis isolates obtained from children stools showed a possible association between the clinical signs and assemblage (Read et al., 2002; Cedillo-Rivera et al., 2003). For example, in 
Cuba children harboring assemblage B infection were more likely to have symptomatology than children infected with assemblage A (Puebla et al., 2014). Assemblage AI is associated with multiple host species and AII is more restricted to humans. In Colombia, two reports have demonstrated the prevalence of assemblages among humans in two areas of the country. In the northwest province of Bolivar, molecular characterization of Giardia has identified Assemblage A (5.1\%) and Assemblage B (92.3\%) (ArroyoSalgado et al., 2013). Recently, another report in the center of the country (Tolima) suggests that the distributions of Assemblage A (48\%) and B (52\%) are similar. Regarding the sub-assemblages of A and B; AII, BIII and BIV were identified (Rodríguez et al., 2014).

The advent of molecular biology techniques has allowed the identification of target candidates for the molecular diagnosis of Giardia such as SSU rDNA, $\beta$-giardin, tpi and gdh (Yang et al., 2014; Amar et al., 2002; Almeida et al., 2010; Bertrand et al., 2005; Lalle et al., 2005). These markers have demonstrated that cryptic infection is evident and in some cases the prevalence of infection can change from $5.8 \%$ to $31.5 \%$ suggesting the need to implement molecular diagnosis instead of microscopy in Giardia (Mejia et al., 2013). The aim of the study was to determine the prevalence of Giardia infection by means of molecular methods via PCR targeting three molecular markers ( $g d h$, SSU rDNA and tpi). Sensitivity, specificity and statistical concordance (kappa index) with microscopy was calculated. Finally, positive samples were analyzed in order to discriminate the genetic assemblages circulating in a geographically restricted population of children in Colombia. This is the first time that a Colombian cohort with Giardia infection is genotyped by means of DNA sequencing.

\section{Materials and methods}

\subsection{Population study}

We obtained 181 fecal samples from asymptomatic children under 16 years old from the hamlet La Vírgen, Cundinamarca (Colombia) that voluntarily accepted to participate in the study. The children were physically examined to verify their asymptomatic status. The ethical clearance of this study was followed by the ethics of Helsinki declaration and resolution No. 008430 of 1993 from the Ministry of Health from Colombia and "El Código del Menor". The study protocol was approved by the ethics committee from the faculty of Medicine of the Universidad Nacional de Colombia under the Number 0045763. La Virgen hamlet is located in the department of Cundinamarca at $4^{\circ} 45^{\prime}$ north latitude and $74^{\circ} 32^{\prime}$ west longitude with an altitude of $1050 \mathrm{~m}$ above sea level. The overall percentage of unsatisfied basic needs (UBS) is $58 \%$.

\subsection{Fecal samples collection, microscopic diagnosis and DNA extraction}

The fecal samples were collected in plastic recipients, labeled and conserved in refrigerated boxes. The samples were divided in two parts: one part was fixed in a proportion $(1: 4)$ in ethanol $70 \%$ and stored at $-20^{\circ} \mathrm{C}$ for DNA extraction. The other part was used for conducting Kato-katz, modified Richie-Frick method and direct microcopy examination for diagnosis of intestinal parasites (Chaves et al., 1979). For the microscopic diagnosis of intestinal parasites, fecal samples were examined by experimented microscopists using wet mount smears in saline solution and by triplicate. All slides were examined by three experienced parasitologists for quality check. From each sample, $250 \mathrm{mg}$ were submitted to DNA extraction using the QIAmp DNA Stool Mini Kit (Qiagen, Hilden, Germany) according to manufactureŕs instructions. Genomic DNA was preserved at $-20^{\circ} \mathrm{C}$ until analysis.

\subsection{Molecular diagnosis}

Detection of $G$. duodenalis DNA was carried out using SSU rDNA, gdh and tpi. For SSU rDNA subunit, a nested PCR was done using specific primers RH11 and RH4 in the first round, and GiarF and GiarR in the second round. For gdh locus, a semi-nested PCR was done using primers GDHeF, GDHiF and GDHiR. For the tpi locus, a nested PCR was done using primers AL3543 and AL3546 in the first round, and AL3544 and AL3545 in the second round. PCR assays were performed on a SensoQuest 96 Well Thermal-cycler (LabCycler) using the GoTaq Green Master Mix (Promega). Concentration of primers in PCR reactions was $10 \mu \mathrm{M}$ each and we added $5 \mu \mathrm{L}$ of DNA, the samples were run in duplicate. All reactions started with an activation-denaturation step at $94^{\circ} \mathrm{C}$ for 5 min and then were carried out for 40 cycles, each consisting of $94{ }^{\circ} \mathrm{C}$ for $30 \mathrm{~s}$, an annealing step of $30 \mathrm{~s}$ at a temperature that varied from 50 to $58{ }^{\circ} \mathrm{C}$ depending on the marker as reported elsewhere (Feng and Xiao, 2011), and of $72{ }^{\circ} \mathrm{C}$ of extension for $30 \mathrm{~s}$. A final extension step was carried out at $72{ }^{\circ} \mathrm{C}$ for $7 \mathrm{~min}$. PCR products were electrophoresed on GelRed-stained $2 \%$ agarose gels in TAE $1 \times$ at $100 \mathrm{~V}$ for $30 \mathrm{~min}$. Positive (WB and GS strains) and negative (water) controls were always included in the reactions.

\subsection{Molecular characterization}

For the discrimination of $G$. duodenalis genetic assemblages (A and B) we employed five strategies: (i) PCR-RFLP of gdh, (ii) assemblage specific PCR primers of tpi as reported by Bertrand et al., 2005, (iii) assemblage specific PCR primers of GL50581_3242 Hypothetical protein, (iv) assemblage specific PCR primers of GL50581_725: Protein 21.1 as reported elsewhere (Vanni et al., 2012) and (v) Direct Sanger sequencing of gdh locus (Read et al., 2004; Bertrand et al., 2005). For the discrimination of sub-assemblages AI, AII, BIII and BIV we employed a PCR-RFLP targeting the gdh locus. The sequences of the primers employed are listed in Table 1 and the algorithm employed for the discrimination of $G$. duodenalis assemblages and sub-assemblages is shown in Fig. 1.

Table 1

List and sequence of primers used for the molecular diagnosis and characterization of G. duodenalis.

\begin{tabular}{|c|c|c|}
\hline Gene & Primer $\left(5^{\prime}-3^{\prime}\right)$ & Reference \\
\hline $\begin{array}{l}\text { SSU } \\
\text { rDNA }\end{array}$ & $\begin{array}{l}\text { RH11 (CATCCGGTCGATCCTGCC) } \\
\text { RH4 } \\
\text { (AGTCGAACCCTGATTCTCCGCCCAGG) } \\
\text { GiarF (GACGCTCTCCCCAAGGAC) } \\
\text { GiarR (CTGCGTCACGCTGCTCG) }\end{array}$ & $\begin{array}{l}\text { Hopkins et al. (1997) } \\
\text { Hopkins et al. (1997) } \\
\text { Hopkins et al. (1997) } \\
\text { Hopkins et al. (1997) }\end{array}$ \\
\hline gdh & $\begin{array}{l}\text { GDHeF (TCAACGTYAAYCGYGGYTTCCGT) } \\
\text { GDHiF (CAGTACAACTCYGCTCTCGG) } \\
\text { GDHiR (GTTRTCCTTGCACATCTCC) }\end{array}$ & $\begin{array}{l}\text { Read et al. (2002) } \\
\text { Read et al. (2002) } \\
\text { Read et al. (2002) }\end{array}$ \\
\hline tpi & $\begin{array}{l}\text { AL3543 (AAATIATGCCTGCTCGTCG) } \\
\text { AL3546 (CAAACCTTITCCGCAAACC) } \\
\text { AL3544 (CCCTTCATCGGIGGTAACTT) } \\
\text { AL3545 (GTGGCCACCACICCCGTGCC) }\end{array}$ & $\begin{array}{l}\text { Sulaiman et al. } \\
\text { (2003) } \\
\text { Sulaiman et al. } \\
\text { (2003) } \\
\text { Sulaiman et al. } \\
\text { (2003) } \\
\text { Sulaiman et al. } \\
\text { (2003) }\end{array}$ \\
\hline 4E1-HP & $\begin{array}{l}\text { A4E1F (AAAGAGATAGTTCGCGATGTC) } \\
\text { A4E1R } \\
\text { (ATTAACAAACAGGGAGACGTATG) } \\
\text { B4E1F (GAAGTCATCTCTGGGGCAAG) } \\
\text { B4E1R (GAAGTCTAGATAAACGTGTCGG) }\end{array}$ & $\begin{array}{l}\text { Vanni et al. (2012) } \\
\text { Vanni et al. (2012) } \\
\text { Vanni et al. (2012) } \\
\text { Vanni et al. (2012) }\end{array}$ \\
\hline $5 \mathrm{C} 1-\mathrm{P} 21$ & $\begin{array}{l}\text { A5C1F (ATGCTAGCCGTAGTTAATAAGG) } \\
\text { A5C1R (ACCGGCCTTATCTACCAGC) } \\
\text { B5C1F (TTAATAGAAATGCTTTCGACACG) } \\
\text { B5C1R (TTGCTACAGCAGAAAGGTGC) }\end{array}$ & $\begin{array}{l}\text { Vanni et al. (2012) } \\
\text { Vanni et al. (2012) } \\
\text { Vanni et al. (2012) } \\
\text { Vanni et al. (2012) }\end{array}$ \\
\hline
\end{tabular}




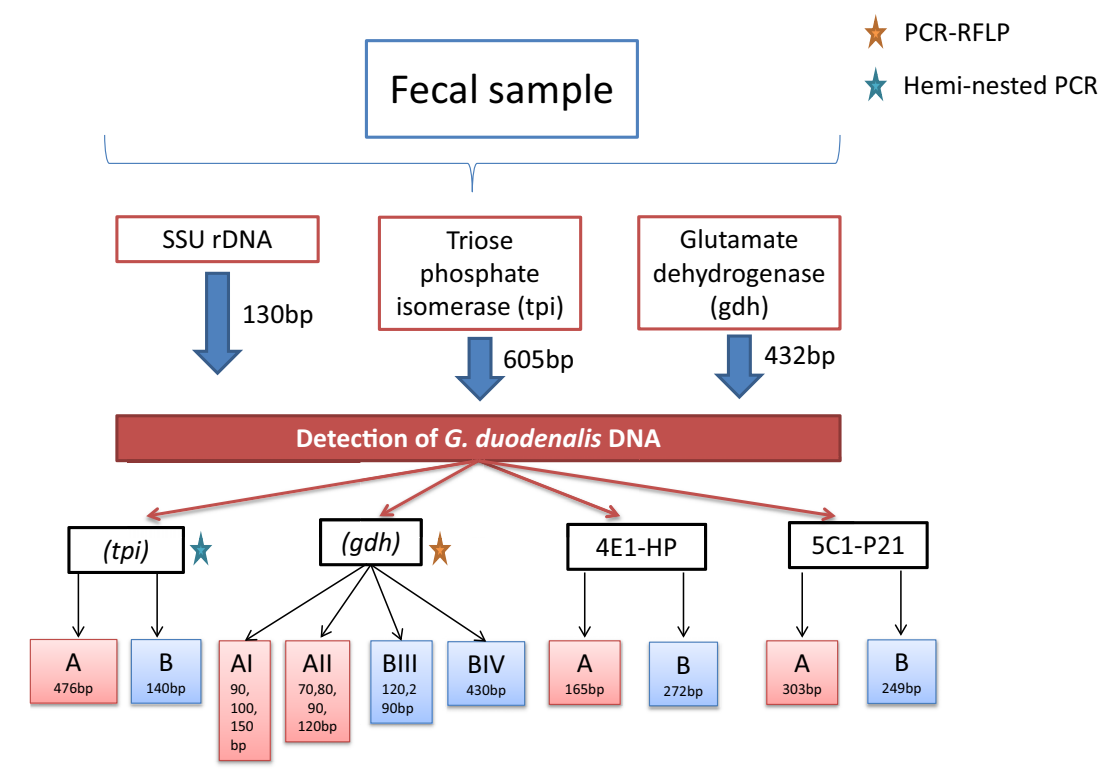

Fig. 1. Algorithm for genotyping of G. duodenalis assemblages in stool samples based on a variety of molecular markers.

PCR assays were performed on a SensoQuest 96 Well Thermalcycler (LabCycler) using the GoTaq Green Master Mix (Promega). Concentration of primers in PCR reactions was $10 \mu \mathrm{M}$ each and we added $5 \mu \mathrm{L}$ of DNA, the samples were run in duplicate. The thermal profile of each marker was according to previous reports. The PCR-RFLP using gdh locus was conducted following the instructions of Read et al., 2004. PCR products were electrophoresed on GelRedstained $2 \%$ agarose gels in TAE $1 \times$ at $100 \mathrm{~V}$ for $30 \mathrm{~min}$. Positive (WBA assemblage and GS-B Assemblage strains) and negative (water) controls were always included in the reactions.

In the case of the direct sequencing of gdh locus, the PCR products were digested with EXOSAP (Affymetrix, USA) and sequenced by the dideoxy-terminal method in an automated capillary sequencer ( $A B 3730$, Applied Biosystems) by both strands. The resulting sequences were edited in MEGA 5.0 and aligned using ClustalW 1.8 with reference sequences from Assemblages AI, AII, BIII and BIV retrieved from GiardiaDB for the molecular characterization (Tamura et al., 2011; Larkin et al., 2007). All edited sequences were deposited in GenBank and assigned accession numbers (KP126735-KP126754). The sequences were evaluated in ModelTest 3.7 where the most appropriate evolutionary model was selected based on the AIC (Akaike Information Criterion). A Maximum Composite Likelihood (MCL) analysis using a Tamura3 parameter was run in RaxML Phylogeny.fr platform. To evaluate the robustness of the nodes in the resulting phylogenetic tree, 1000 bootstrap replicates were performed. The final tree was rooted with Assemblage E retrieved from GiardiaDB since this is a non-human infective genetic assemblage and phylogenetically distant from $\mathrm{A}$ and $\mathrm{B}$ assemblages.

\subsection{Statistical analyses}

To determine the reliability and congruence of the results obtained by molecular means, we calculated the sensitivity, specificity and the kappa index parameters. Microscopy was used as the gold standard because it is the common used technique for the diagnosis of Giardia around the world and specifically for Colombia. The concordance between molecular diagnosis and microscopy was calculated using the kappa index $(\kappa)$. Cohen's kappa coefficient is a statistical measure of inter-rater agreement or inter-annotator agreement for qualitative (categorical) items
(Viera and Garrett, 2005). It is generally thought to be a more robust measure than simple percent agreement calculation since $\kappa$ takes into account the agreement occurring by chance. We calculated the concordance among the five molecular strategies to genotype Giardia populations.

\section{Results}

\subsection{Prevalence of intestinal parasites and Giardia in fecal samples}

The prevalence of intestinal parasites in collected stool samples were: Ascaris lumbricoides (7\%), Trichuris trichiura (14\%), Hookworm (15\%), Hymenolepis nana (1\%), Chilomastix mesnili (3\%), Entamoeba histolytica/Entamoeba dispar (18\%), Escherichia coli (34\%), Endolimax nana (45\%), Iodamoeba butschlii (7\%), Blastocystis (34\%), Entamoeba hartmanni (3\%) and G. duodenalis (13\%).

\subsection{Molecular diagnosis of $G$. duodenalis}

We applied SSU rDNA, tpi and gdh for the molecular diagnosis of G. duodenalis. The prevalence using SSU rDNA was $80 \%$, tpi $77 \%$ and gdh $76 \%$ as shown in Fig. 2. The results showed a dramatic change in the prevalence of $G$. duodenalis infection when comparing molecular diagnosis vs. microscopy. Likewise, we calculated sensitivity, specificity and kappa index $(\kappa)$ parameters to determine the features of PCR compared to microscopy observing a lack of statistical congruence using microscopy for this comparison (Table 2). In terms of concordance, $g d h$ locus showed to be more concordant with microscopy followed by SSU rDNA and tpi locus.

\subsection{Genotyping analysis of $\mathrm{G}$. duodenalis}

Regarding the $G$. duodenalis assemblages, the use of different molecular markers allowed us to determine in a reliable manner the distribution of assemblages across the population. We took 138 samples that were positive for the three molecular markers employed for the molecular diagnosis to conduct the genetic discrimination of assemblages. Therefore, based on the four markers for the identification of assemblages $A$ and $B$ that infect humans we observed assemblage A (3\%), assemblage B (90\%) and mixed infections by assemblages $A+B(7 \%)$ (The mixed infections were 


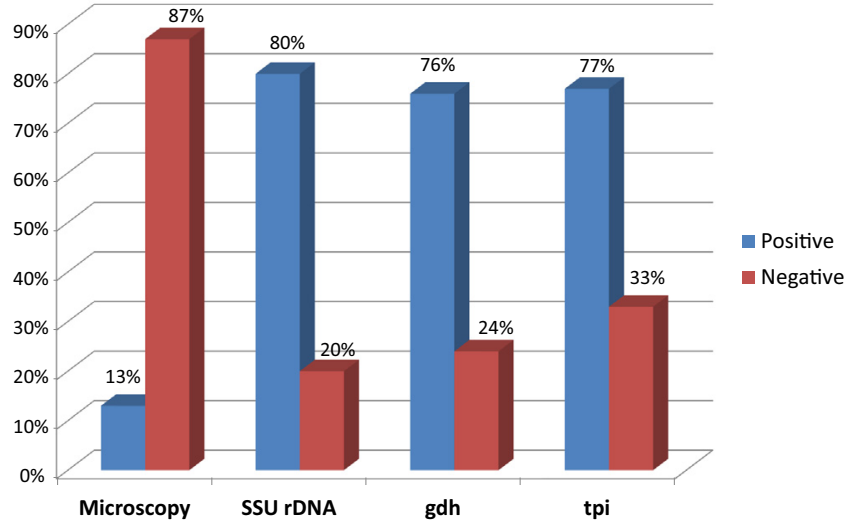

Fig. 2. Prevalence of detection via microscopy and PCR targeting SSU rDNA, tpi and gdh loci.

Table 2

Parameters of sensitivity, specificity and kappa index to determine concordance using microscopy as the standard.

\begin{tabular}{llllll}
\hline Target & $N$ & Sensitivity (\%) & Specificity (\%) & KI & CI 95\% \\
\hline SSU rDNA & 181 & 15 & 95 & 0.044 & $0-0.1378$ \\
tpi & 181 & 13 & 93 & 0.0347 & $0-0.0849$ \\
gdh & 181 & 14.5 & 95 & 0.0507 & $0-0.1544$ \\
\hline
\end{tabular}

only detected when using assemblage-specific primers by Vanni et al., 2012). Those samples that were typed as assemblage $\bar{A}$ and B were submitted to PCR-RFLP (gdh locus) restriction using Nla IV and RsaI enzymes. The results showed that 9 samples (64\%) were $\mathrm{AI}$ and 5 samples (36\%) were typed as AII; in the case of sub-assemblages of B, 123 samples were typed as BIV, only one sample was typed as BIII.

The gdh locus DNA sequences were used to construct a Maximum Composite Likelihood tree. The selected substitution model was HKY85 with a gamma-shape parameter of 88.926, a transition/transversion ratio of 8.537, and a proportion of invariant sites of 0.356 . We observed absence of allele sequence heterozygosity (ASH) for assemblage A samples and 13/124 assemblage B samples showed ASH (These were excluded for the phylogenetic reconstruction). The samples were typed as AI, AII, BIII and BIV assemblages according to the topology of the tree and using the reference sequences retrieved from GiardiaDB. The phylogenetic tree topology showed that samples typed as Assemblage B were highly homogenous but those typed as AII and AI showed a high frequency of genetic diversity as an evidence of an elevated number of SNP's in the multiple alignments. This clearly shows divergence in the samples analyzed (Fig. 3; Tables S1 and S2). The results of the DNA sequences showed congruence with the other four strategies employed for discriminating Giardia assemblages.

\section{Discussion}

Giardiasis still represents a serious problem of public health affecting around 200 million people around the globe. Despite of the understanding of the etiology of this infection, the current techniques employed for the diagnosis of Giardia are not considered very sensitive and PCR has emerged as an alternative to solve the sensitivity issue for the diagnosis of this parasitic infection. $G$. duodenalis displays a remarkable genetic diversity evidenced in 8 genetic clusters and named as assemblages. The use of this nomenclature has allowed the scientific community to determine the assemblages circulating in humans and animals around the world
(Ryan and Cacciò, 2013). This approach to understand the molecular epidemiology of Giardia has been of paramount relevance to determine disease features such as clinical association, resistance to treatment and transmission dynamics of the assemblages (Feng and Xiao, 2011; Cacciò and Sprong, 2010; Breathnach et al., 2010; Homan and Mank, 2001). Likewise, the advent of molecular tools has permitted to obtain DNA sequences from specific genes across the Giardia genome to establish epidemiological circuits and elucidate the zoonotic potential of giardiasis (Ryan and Cacciò, 2013). Herein, we compare three targets for the molecular diagnosis of Giardia and reported a reliable description of G. duodenalis assemblages circulating in children from a rural area in central Colombia.

In the case of Giardia, a broad number of comparisons have been conducted showing that when PCR is applied, the prevalence of infection increases (Koehler et al., 2014; Asher et al., 2012; Yang et al., 2014). We applied SSU rDNA, tpi, and gdh to 181 fecal samples, the ranges of prevalence changed from $13 \%$ by microscopy to $76-80 \%$ using the molecular markers. This increase in the prevalence of infection using molecular markers has been reported before using SSU rDNA regions as shown by Mejia et al., 2013. When applying qPCR methods compared to microscopy the prevalence changed from $5.8 \%$ to $31.5 \%$ for the case of Giardia. In our case, we observed that $18 \mathrm{~S}$ was more sensitive than tpi and gdh suggesting that this locus is ideal for the detection of Giardia DNA (Fig. 2) and congruent with data previously reported. Our conclusions and results are confirmatory and supported by other authors that imply the same premise (Mejia et al., 2013; Almeida et al., 2010; Traub et al., 2004; Boadi et al., in press).

The geographical distribution of the $G$. duodenalis assemblages is intriguing since there is a lack of geographical structuring across the globe (in the case of the human-infective assemblages A and B). In the Americas, there exist areas with differential distribution of assemblages. Some reports from Mexico, Brazil and Colombia identifies higher frequencies of assemblage A (Eligio-García et al., 2008; Kohli et al., 2008; Rodríguez et al., 2014) while in Nicaragua, Argentina and also Colombia some authors report the predominance of assemblage B (Minvielle et al., 2008; Arroyo-Salgado et al., 2013; Lebbad et al., 2008). This suggests that the distribution is not geographically associated and is more linked to the socioeco-epidemiological factors of the population studied. Herein, we observed a tailored frequency of assemblage B genotypes that is considered more associated to humans than zoonotic; this is also congruent with the abundance of assemblage $B$ in animals from Colombia (Fayer et al., 2012; Santín et al., 2013). However, a low frequency of samples typed as assemblage A were found (14/ 181). Curiously, the most frequent sub-assemblage was AI (9/14) that has been more associated to animals than humans. This could be attributed to the lack of water treatment of the population studied and a close contact with dogs and cats in the region. The presence of AI could be possible due to contamination of public water with raw sewage from animal and human sources (Helmy et al., 2009; Volotão et al., 2007). This is also supported by the phylogenetic reconstruction where the Assemblage A samples showed higher genetic diversity than Assemblage B suggesting that different Assemblage A populations are circulating in that epidemiological focus (Fig. 3). It is interesting to mention that this population has been screened in the last 10 years and just now the genotypes incriminated have been determined. It is possible that for this geographical area there is a possible adaptation of assemblage B (this genotype might have some mutations that are selectively advantageous) in the population that is intriguingly not causing symptomatology in the patients. We selected this geographical region as part of an institutional project which aims to determine the intestinal parasites in children to provide adequate treatment. 


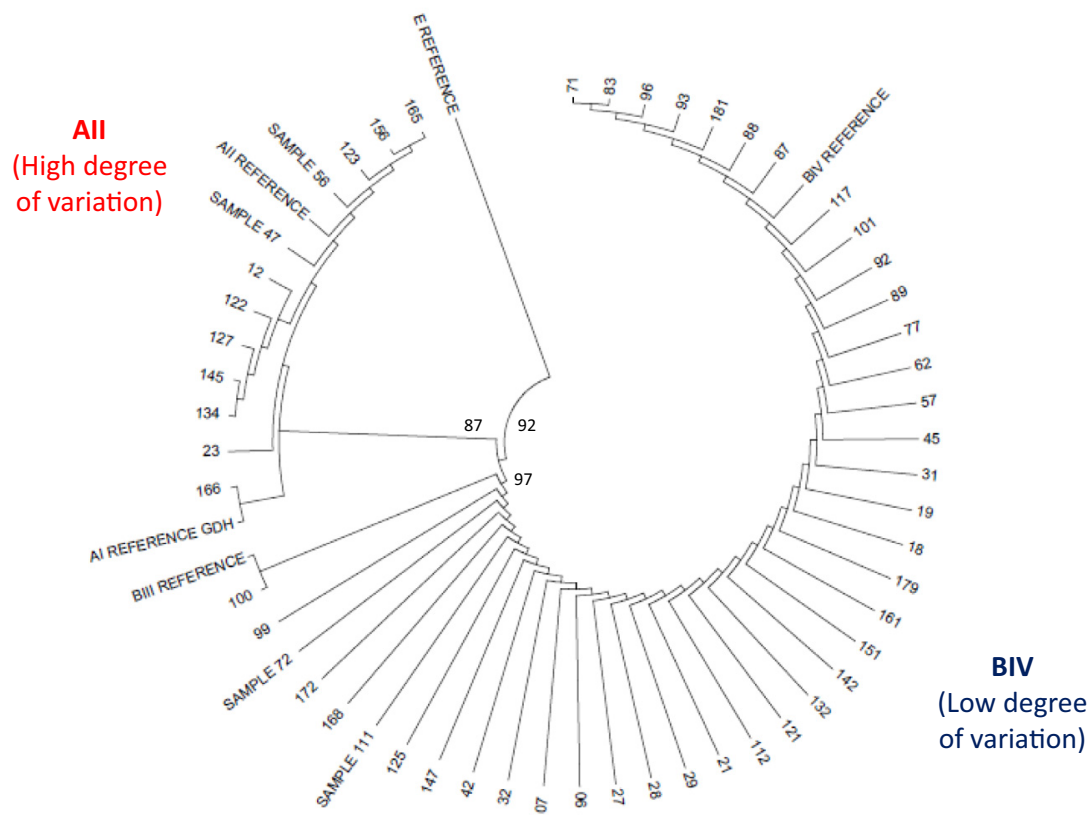

Fig. 3. Maximum Composite Likelihood phylogenetic reconstruction of gdh DNA sequences obtained from the positive samples.

Also, this might be supported by the high frequency of Assemblage BIV in the population and the lack of genetic diversity when analyzing gdh locus DNA sequences. These findings support an adaptation of BIV to the population but to fulfill this hypothesis it is necessary to conduct a case-control retrospective study in the same population. Also, we need to sample the Giardia populations circulating in dogs, cats and livestock in order to provide a more reliable molecular epidemiology circuit of Giardia transmission in that specific region. Another plausible hypothesis might be that the observation of low diversity and high frequency is supported by the idea of a likely epidemic outbreak of BIV infection.

The occurrence of mixed infections was an interesting feature of the findings herein reported. The identification of mixed infection has been lately possible with the use of new sets of primers that are assemblage-specific providing evidence of super infection across populations (Vinni et al., 2012; Geurden et al., 2008). We observed that $7 \%$ of the patients were co-infected with $A$ and $B$ assemblages, this is not novel since this vulnerable population is highly exposed to multiple infections of a broad number of sources that makes this plausible.

The molecular epidemiology is a valuable tool to understand the transmission dynamics of a broad number of pathogens. One of the first requirements to conduct reliable molecular epidemiology studies is the homogenization of the nomenclature. However, this has not been done in G. duodenalis and is mandatory in order to compare genotypes and genotyping strategies across the globe. We observed that molecular diagnosis of Giardia is necessary to unravel the real prevalence of this infection and the typing of the parasites is helpful to determine the transmission dynamics of this pathogen. Our results showed the importance of PCR in the diagnosis of Giardia and typing to understand the transmission features of this pathogen in a specific area and population. This is the first time that direct DNA sequencing is performed in Colombian samples and provides interesting information about the allelic diversity of $g d h$ in this region. We encourage the scientific community to pursue studies based on molecular diagnosis and systematic typing of Giardia populations in Latin-America where the information is almost scarce.

\section{Acknowledgements}

We thank Jairo Fonseca, Nicolás Lemus, Nicolás Castillo and Carlos Clavijo for their support in this work. This work was supported by funds and reagents from Unidad Clínico-Molecular de Enfermedades Infecciosas from Universidad del Rosario and the research division of Universidad Nacional de Colombia, Facultad de Medicina. JDR is principal professor at Universidad del Rosario.

\section{Appendix A. Supplementary data}

Supplementary data associated with this article can be found, in the online version, at http://dx.doi.org/10.1016/j.meegid.2015.03. 015.

\section{References}

Almeida, A., Pozio, E., Cacciò, S.M., 2010. Genotyping of Giardia duodenalis cysts by new real-time PCR assays for detection of mixed infections in human samples. Appl. Environ. Microbiol. 76, 1895-1901.

Amar, C.F., Dear, P.H., Pedraza-Díaz, S., Looker, N., Linnane, E., McLauchlin, J., 2002. Sensitive PCR-restriction fragment length polymorphism assay for detection and genotyping of Giardia duodenalis in human feces. J. Clin. Microbiol. 40, 446452 .

Andrews, R.H., Monis, P.T., Ey, P.L., Mayrhofer, G., 1998. Comparison of the levels of intra-specific genetic variation within Giardia muris and Giardia intestinalis. Int J. Parasitol. 28, 1179-1185.

Arroyo-Salgado, B., Buelvas-Montes, Y., Villalba-Vizcaíno, V., Salomón-Arzuza, O. 2013. Genetic profiling of Giardia intestinalis by polimerase chain in human and dogs samples of Colombian Caribean Coast. Enferm. Infecc. Microbiol. Clin. 32 424-427.

Asher, A.J., Waldron, L.S., Power, M.L., 2012. Evaluation of a PCR protocol for sensitive detection of Giardia intestinalis in human faeces. Parasitol. Res. 110 $853-858$.

Bertrand, I., Albertini, L., Schwartzbrod, J., 2005. Comparison of two target genes for detection and genotyping of Giardia lamblia in human feces by PCR and PCRrestriction fragment length polymorphism. J. Clin. Microbiol. 43, 5940-5944.

Breathnach, A.S., McHugh, T.D., Butcher, P.D., 2010. Prevalence and clinical correlations of genetic subtypes of Giardia lamblia in an urban setting. Epidemiol. Inf. 138, 1459-1467.

Boadi, S., Polley, S.D., Kilburn, S., Mills, G.A., Chiodini, P.L., in press. A critical assessment of two real-time PCR assays targeting the (SSU) rRNA and gdh genes for the molecular identification of Giardia intestinalis in a clinical laboratory. J. Clin. Pathol. http://dx.doi.org/10.1136/iclinpath-2014-202224. 
Cacciò, S.M., Sprong, H., 2010. Giardia duodenalis: genetic recombination and its implications for taxonomy and molecular epidemiology. Exp. Parasitol. 124, 107-112.

Cedillo-Rivera, R., Darby, J.M., Enciso-Moreno, J.A., Ortega-Pierres, G., Ey, P.L., 2003. Genetic homogeneity of axenic isolates of Giardia intestinalis derived from acute and chronically infected individuals in Mexico. Parasitol. Res. 90, 119-123.

Chaves, A., Alcantara, O.S., Carvalho, O.S., Santos, J.S., 1979. Estudo comparativo dos métodos coprológicos de Lutz, Kato-Katz e Faust modificado. Rev. Saude Publ. 13, 348-352.

Chaves Mdel, P., Fernández, J.A., Ospina, I., López, M.C., Moncada, L., Reyes, P., 2007. Giardia duodenalis prevalence and associated risk factors in preschool and school-age children of rural Colombia. Biomedica 27, 345-351.

Eligio-García, L., Cortes-Campos, A., Cota-Guajardo, S., Gaxiola, S., Jiménez-Cardoso E., 2008. Frequency of Giardia intestinalis assemblages isolated from dogs and humans in a community from Culiacan, Sinaloa, Mexico using beta-giardin restriction gene. Vet. Parasitol. 156, 205-209.

Fayer, R., Santin, M., Macarisin, D., 2012. Detection of concurrent infection of dairy cattle with Blastocystis, Cryptosporidium, Giardia, and Enterocytozoon by molecular and microscopic methods. Parasitol. Res. 111, 1349-1355.

Feng, Y., Xiao, L., 2011. Zoonotic potential and molecular epidemiology of Giardia species and giardiasis. Clin. Microbiol. Rev. 24, 110-140.

Giraldo-Gómez, J.M.I., Lora, F., Henao, L.H., Mejía, S., Gómez-Marín, J.E., 2005 Prevalence of giardiasis and intestinal parasites in pre-school children from homes being attended as part of a state programme in Armenia, Colombia. Rev. Salud Publ. Bogota 73, 327-338.

Geurden, T., Berkvens, D., Casaert, S., Vercruysse, I., Claerebout, E., 2008. A Bayesian evaluation of three diagnostic assays for the detection of Giardia duodenalis in symptomatic and asymptomatic dogs. Vet. Parasitol. 157, 14-20.

Haque, R., Roy, S., Kabir, M., Stroup, S.E., Mondal, D., Houpt, E.R., 2005. Giardia assemblage A infection and diarrhea in Bangladesh. J. Inf. Dis. 192, 2171-2173.

Helmy, M.M., Abdel-Fattah, H.S., Rashed, L., 2009. Real-time PCR/RFLP assay to detect Giardia intestinalis genotypes in human isolates with diarrhea in Egypt. J. Parasitol. 95, 1000-1004.

Homan, W.L., Mank, T.G., 2001. Human giardiasis: genotype linked differences in clinical symptomatology. Int. J. Parasitol. 318, 822-826.

Koehler, A.V., Jex, A.R., Haydon, S.R., Stevens, M.A., Gasser, R.B., 2014 Giardia/giardiasis - a perspective on diagnostic and analytical tools. Biotechnol. Adv. 32, 280-289.

Kohli, A., Bushen, O.Y., Pinkerton, R.C., Houpt, E., Newman, R.D., Sears, C.L., Lima A.A., Guerrant, R.L., 2008. Giardia duodenalis assemblage, clinical presentation and markers of intestinal inflammation in Brazilian children. Trans. R. Soc. Trop. Med. Hyg. 102, 718-725.

Hopkins, R.M., Meloni, B.P., Groth, D.M., Wetherall, J.D., Reynoldson, J.A., Thompson, R.C., 1997. Ribosomal RNA sequencing reveals differences between the genotypes of Giardia isolates recovered from humans and dogs living in the same locality. J. Parasitol. 83, 44-51.

Lalle, M., Pozio, E., Capelli, G., Bruschi, F., Crotti, D., Caccio, S.M., 2005. Genetic heterogeneity at the beta-giardin locus among human and animal isolates of Giardia duodenalis and identification of potentially zoonotic subgenotypes. Int. J. Parasitol. 35, 207-213.

Larkin, M.A., Blackshields, G., Brown, N.P., Chenna, R., McGettigan, P.A., McWilliam, H., Valentin, F., Wallace, I.M., Wilm, A., Lopez, R., Thompson, J.D., Gibson, T.J., Higgins, D.G., 2007. ClustalW and ClustalX version 2. Bioinformatics 23, 29472948. http://dx.doi.org/10.1093/bioinformatics/btm404.

Lebbad, M., Ankarklev, J., Tellez, A., Leiva, B., Andersson, J.O., Svärd, S., 2008. Dominance of Giardia assemblage B in León Nicaragua. Acta Trop. 106, 44-53.

Lora-Suárez, F., Marín-Vásquez, C., Loango, N., Gallego, M., Torres, E., González M.M., et al., 2002. Giardiasis in children living in post-earthquake camps from Armenia Colombia. BMC Public Health 2, 5.

Mejia, R., Vicuña, Y., Broncano, N., Sandoval, C., Vaca, M., Chico, M., Cooper, P.J. Nutman, T.B., 2013. A novel, multi-parallel, real-time polymerase chain reaction approach for eight gastrointestinal parasites provides improved diagnostic capabilities to resource-limited at-risk populations. Am. J. Hyg. Trop. Med. 88, 1041-1047.

Minvielle, M.C., Molina, N.B., Polverino, D., Basualdo, J.A., 2008. First genotyping of Giardia lamblia from human and animal feces in Argentina South America. Mem. Inst. Oswaldo Cruz 103, 98-103.

Monis, P.T., Andrews, R.H., Mayrhofer, G., Mackrill, J., Kulda, J., Isaac-Renton, J.L., Ey, P.L., 1998. Novel lineages of Giardia intestinalis identified by genetic analysis of organisms isolated from dogs in Australia. Parasitology 116, 7-19.

Monis, P.T., Thompson, R.C., 2003. Cryptosporidium and Giardia-zoonoses: fact or fiction? Inf. Genet. Evol. 3, 233-244.

Monis, P.T., Caccio, S.M., Thompson, R.C., 2009. Variation in Giardia: towards a taxonomic revision of the genus. Trends Parasitol. 25, 93-100.

Puebla, L.J., Núñez, F.A., Fernández, Y.A., Fraga, J., Rivero, L.R., Millán, I.A., Valdés, L.A., Silva, I.M., 2014. Correlation of Giardia duodenalis assemblages with clinical and epidemiological data in Cuban children. Inf. Genet. Evol. 23, 1-7.

Read, C., Walters, J., Robertson, I.D., Thompson, R.C., 2002. Correlation between genotype of Giardia duodenalis and diarrhoea. Int. J. Parasitol. 32, 229-231.

Read, C.M., Monis, P.T., Thompson, R.C., 2004. Discrimination of all genotypes of Giardia duodenalis at the glutamate dehydrogenase locus using PCR-RFLP. Inf. Genet. Evol. 4, 125-130.

Rodríguez, V., Espinosa, O., Carranza, J.C., Duque, S., Arévalo, A., Clavijo, J.A., et al., 2014. Genotipos de Giardia duodenalis en niños de las guarderías del Instituto Colombiano de Bienestar Familiar y de caninos en Ibagué, Tolima. Colombia. Biomédica 34, 271-281.

Ryan, U., Cacciò, S.M., 2013. Zoonotic potential of Giardia. Int. J. Parasitol. 43, $943-$ 956.

Savioli, L., Smith, H., Thompson, A., 2006. Giardia and Cryptosporidium join the 'Neglected Diseases Initiative'. Trends Parasitol. 22, 203-208.

Santín, M., Cortés Vecino, J.A., Fayer, R., 2013. A large scale molecular study of Giardia duodenalis in horses from Colombia. Vet. Parasitol. 196, 31-36.

Sulaiman, I.M., Fayer, R., Bern, C., Gilman, R.H., Trout, J.M., Schantz, P.M., Das, P., Lal, A.A., Xiao, L., 2003. Triosephosphate isomerase gene characterization and potential zoonotic transmission of Giardia duodenalis. Emerg. Infect. Dis. 9, 1444-1452.

Tamura, K., Peterson, D., Peterson, N., Stecher, G., Nei, M., Kumar, S., 2011. MEGA5: molecular evolutionary genetics analysis using maximum likelihood, evolutionary distance, and maximum parsimony methods. Mol. Biol. Evol. 28, 2731-2739.

Thompson, R.C., 2000. Giardiasis as a re-emerging infectious disease and its zoonotic potential. Int. J. Parasitol. 30, 1259-1267.

Thompson, R.C., 2002. Presidential address: rediscovering parasites using molecular tools-towards revising the taxonomy of Echinococcus, Giardia and Cryptosporidium. Int. J. Parasitol. 32, 493-496.

Traub, R.J., Monis, P.T., Robertson, I., Irwin, P., Mencke, N., Thompson, R.C., 2004. Epidemiological and molecular evidence supports the zoonotic transmission of Giardia among humans and dogs living in the same community. Parasitology $128,253-262$.

Vanni, I., Cacciò, S.M., van Lith, L., Lebbad, M., Svärd, S.G., Pozio, E., Tosini, F., 2012. Detection of Giardia duodenalis assemblages A and B in human feces by simple, assemblage-specific PCR assays. PLoS Negl. Trop. Dis. 6, e1776.

Viera, A.J.K., Garrett, J., 2005. Understanding interobserver agreement: the kappa statistic. Fam. Med. 37, 360-363.

Volotão, A.C., Costa-Macedo, L.M., Haddad, F.S., Brandão, A., Peralta, J.M., Fernandes, O., 2007. Genotyping of Giardia duodenalis from human and animal samples from Brazil using beta-giardin gene: a phylogenetic analysis. Acta Trop. 102, 10-19.

Yang, R., Jacobson, C., Gardner, G., Carmichael, I., Campbell, A.J., Ryan, U., 2014. Development of a quantitative PCR, qPCR for Giardia and analysis of the prevalence, cyst shedding and genotypes of Giardia present in sheep across four states in Australia. Exp. Parasitol. 137, 46-52. 